Cerebrovasc Dis 2007;24:159

DOI: 10.1159/000103627

\section{Reply to the Letter by Bernhardt et al.: Mobilisation 'in Bed' Is Not Mobilisation}

\section{Julien Bogousslavsky}

Department of Neurology and Neurorehabilitation, Swiss Medical Network, Valmont-Genolier Hospitals, Glion-sur-Montreux, Switzerland

The remarks by Bernhardt et al. are welcome. They emphasize the lack of appropriate scientific data in the field of stroke recovery and rehabilitation, so that attempts such as theirs to conduct adequate clinical trials of post-stroke interventions are greatly appreciated. Since stroke and its consequences will never be eradicated by either prevention or acute therapy, it is of utmost importance to focus resources on the facilitation of recovery, a domain which has been largely 'snobbed' by a large number of stroke experts.

However, it may be misleading to equate mobilization with getting out of bed. Indeed, while it is correct that mobilization in bed is not synonymous with mobilization with sitting and standing up, it is clear that useful mobilization strategies and physiotherapy can be provided in bed, and an early start, 'immediately' after admission in coordination with acute therapy, may be recommended, despite the present lack of controlled studies. The emphasis is on getting out of bed 'early', but 'early' may still vary according to the local systems, mainly because of the lack of scientifically established protocols. In several places, getting out of bed after 2 days is certainly not 'turning the clock back', since several local protocols may still recommend getting up only after 1 week. In other places that already implement earlier mobilization, there is of course no reason to abandon that practice, provided it remains coordinated with acute neuromonitoring and does not interfere with acute-phase management.

J. Bogousslavsky, MD

Department of Neurology and Neurorehabilitation

Swiss Medical Network, Valmont-Genolier Hospitals

CH-1823 Glion-sur-Montreux (Switzerland)

Tel. +4121962 3700, Fax +41219623838

E-Mail jbogousslavsky@valmontgenolier.ch 